\title{
A Guide for Assessing a Patient's Level of Personal Responsibility for Diabetes Management
}

\author{
Robert M. Anderson and Robert W. Genthner ${ }^{\mathrm{b}}$ \\ 'University of Michigan Diabetes Research and Training Center, Ann Arbor, Michigan and ${ }^{\circ}$ Lexington, Kentucky (U.S.A.)
}

(Received June 1st, 1990)

(Accepted August 21st, 1990)

\begin{abstract}
This paper presents a guide for assessing $a$ diabetic patient's level of personal responsibility. In the general population, high levels of personal responsibility have been shown to be related to psychological well-being and are especially appropriate for chronic disease such as diabetes. With diabetes, patients are required to deliver virtually all of the daily self-care. Successful adaptation to this role is enhanced when patients are able to accept personal responsibility for having and treating their diabetes. The paper describes five levels of personal responsibility starting with the lowest level in which patients feel overwhelmed, hopeless, and helpless and ending with the highest level in which patients accept diabetes as a fact of their lives and fully accept responsibility for it. A discussion of assessing the patient's level of personal responsibility and responding appropriately to patients at different levels is included.
\end{abstract}

Keywords: Personal responsibility; Psychosocial adjustment; Behavior; Diabetes; Attitudes.

\footnotetext{
R.M. Anderson, EdD is an Assistant Research Scientist.

R.W. Genthner, PhD is a Clinical Psychologist in private practice.
}

\section{Introduction/background}

The paper will present a guide for assessing a diabetic patient's level of personal responsibility. The Personal Responsibility (PR) Assessment System has been found to be useful for helping diabetes educators conduct a pre-education assessment of a diabetic patient's psychosocial adjustment to diabetes [1]. Based on this assessment educators can set realistic educational goals with patients for improved psychosocial adaptation. The PR System can then be used for post-educational assessment to document changes in patients' attitudes about their personal responsibility for diabetes. Participation in a patient education program has been shown to be associated with an increased level of personal responsibility for diabetes which was sustained at 6 months follow-up [2]. Using this guide educators can assess the level of personal responsibility at which given patients are functioning. Knowing the characteristics of a patient's behavior and attitudes at each of the five levels of personal responsibility can assist in the choice of educational interventions.

In the general population, helping persons accept increased levels of personal responsibility for their lives is associated with improved psychological functioning and well- 
being [3,4]. Helping patients accept greater levels of personal responsibility for their diabetes should enhance their level of self-care and improve their psychological and social adaptation to having and treating diabetes [5]. The PR Assessment System is a method of assessing the personal meaning that patients give to diabetes. The PR assessment system has five levels that form a continuum of interpretations to having and treating diabetes. At the lowest level, \#1, patients feel overwhelmed by diabetes and perceived themselves as hopeless and helpless victims. At the highest level, \#5, patients accept diabetes as a fact of their lives and take responsibility for their psychological and behavioral response to it.

The Personal Responsibility (PR) Assessment System is a valid and reliable psychological measure which was originally developed for psychotherapy practice and has been adpated for use in diabetes education. The concurrent validity of the scale was supported by the finding that personal responsibility ratings, using taped interviews, were significantly correlated with 15 scales of the California Personality Inventory, including an average score which was a measure of overall adjustment [6]. Concurrent validity was further supported in a study which showed that levels of personal responsibility correlated negatively with scores on the Taylor Manifest Anxiety Scale [7]. The reliability of the PR rating system is supported by the high levels of interrater reliability (coefficient $\alpha s$ of 0.80 to 0.9 ) that have been established with graduate students who have been trained to assess levels of personal responsibility $[6,7]$.

\section{Philosophical assumptions}

The PR assessment system rests on certain key philosophical assumptions. First, the system assumes that human responsibility is a fact of life. Human beings make choices and the choices they make have consequences, therefore persons are responsible for the con- sequences of their choices [8]. Second, the system assumes that human beings create and are therefore responsible for the meaning of their lives. Persons do not create or control all the circumstances in their lives (e.g., having diabetes) but they do give meaning to those circumstances [9]. Some patients view having diabetes as a disaster while others view having it as a challenge [10]. The meaning of life events such as diabetes is not inherent in the event but rather is created by the person with the diabetes [11].

Third, the PR system assumes that human beings possess an inherent drive toward health and well-being [12]. People possess many barriers to realizing their human potential, but as they work to overcome these barriers they move to higher levels of human growth and personal responsibility. This drive is facilitated to the degree that their physical and psychological needs for safety are met [13]. Creating a psychologically safe environment for patients during diabetes education increases the probability that they will learn and accept greater responsibility for their diabetes $[1,14]$.

A word of caution - the PR system does not cover all the psychosocial issues associated with diabetes. It is, however, a useful method for understanding and influencing psychological and social adaptation to diabetes. Although the PR system has been used primarily in diabetes education it could be adapted to use in other patient education programs as well.

\section{The five levels of personal responsibility}

The following is a general description of each of the five levels, including a description of characteristics that will assist the educator in identifying the PR level of patients.

\section{Level 1}

At this level patients take no responsibility for the management of their diabetes. They are apathetic and overwhelmed by life and 
rarely accept the consequences of their actions. They are defeated victims who have given up.

Energy. Patients at Level 1 lack any directed energy. A sense of helplessness about their diabetes is characteristic. When patients do act their actions tend to be unrealistic and nongoal related. At this level patients spend only the minimal amount of energy on diabetes necessary to survive. They show little interest in self-care, including personal hygiene and grooming.

Focus. The life focus of patients at Level 1 is almost entirely outward with virtually no self-exploration or insight. When confronted with their outlook or behavior, patients resign themselves to the fact that "nothing pays off anyway." Patients do not get angry easily at Level 1 since they feel "it wouldn't do any good." In fact, overt anger is a sign that a patient is moving to a higher level. Getting angry is useful for patients at this level because it indicates that they are beginning to fight back. At Level 1 patients are extremely dependent on the doctor, nurse, hospital, their relatives and other care givers for the management of their diabetes.

Crisis management. At Level 1 crises are resolved, if at all, only by going to someone else for help. Patients at Level 1 who become acutely ill would either do nothing and wait for others to discover the problem or merely inform someone that they are sick. Crises reinforce their overall sense of victimization. Patients do not feel responsible for anything that happens, so they do not feel obliged to do anything about it.

Language. At Level 1 patients talk about the problems with their diabetes as if they were inevitable and all caused by unfortunate circumstances. They describe themselves as having no control or mastery over diabetes and its self-care. Examples of Level 1 verbalizations are: "What's the use of following a diet? You can never lose weight." "Diabetes has ruined everything for me." "It's impossi- ble to do all they stuff they want to do." "Someone else has to give me my insulin. I can't learn it."

Example of a patient educator interchange with a patient functioning at Level 1.

Patient: "The world's always against you. It isn't worthy trying . Even my husband doesn't care that I have diabetes."

Educator: "I hear your unhappiness. I wonder, have you tried to talk to your husband?"

Patient: "It wouldn't do any good; nothing ever does."

There are a number of indications that this patient is at Level 1. The patient has externalized all responsibility and has seemingly given up. She sees her problems as caused by her husband, her diabetes and the world in general. Level 1 is also indicated by her reaction to the educator's suggestion of action; she goes deeper into her despair. Another indicator of Level 1 is her use of the word "it" or "you" as the major subject which depersonalizes even her sense of victimization, i.e., "The world is against you" rather than "The world is against me." If patients at Level 1 try to manipulate others by representing themselves as extremely victimized they would be rated 1.5 or 2.0 . Trying to gain some advantage through this kind of manipulation implies that they feel they are able to do something about their state, however indirectly.

\section{Level 2}

At Level 2 patients depersonalize their approach to diabetes. However, they show some signs of personal responsibility by their angry/blaming tone and their unwillingness to give up. At Level 2 patients often talk about their problems in abstract terms, without personal references. They see specific forces outside of themselves as the cause of their problems with diabetes and its self-care. Because patients at Level 2 are pursuing a solution to their problems by anger or depersonalized blaming, they do have some sense of personal responsibility. 
Energy. Patients at Level 2 may mobilize their energy, especially if they are fighting back. This fighting back is directed at persons and forces they consider threatening. They often avoid challenging directly those they are angry at, but may instead engage in backbiting and gossip. Patients at Level 2 may spend a lot of energy blaming doctors, nurses, family members, and hospitals for letting them down.

Focus. The focus of patients at Level 2 is both past and future, but seldom present. They are recovering from past struggles and are anticipating future problems. At Level 2 people rarely enjoy what they are doing now and gain pleasure in accomplishments retrospectively, if at all. Blaming is the major indication that patients are functioning at Level 2. They see their problems as caused by circumstances without seeing their role in the situation at all. At Level 2 patients frequently indulge in self-pity. Self-pity may take the form of whining submissiveness or active selfrighteousness. For example, patients may expect people to spend a lot of time and energy feeling sorry for them because of their diabetes or claim that no one understands how tough it is for them. Unlike patients at Level 1, persons at Level 2 actively pursue the perspective of themselves as victims and use that perspective to try to meet their needs. Even joy and happiness are seen as brought on externally rather than earned or emanating from within themselves.

Depersonalization of a problem is a typical Level 2 behavior. Patients may not actively blame their troubles on something or someone else, but they will find a way to disassociate themselves from their problems. These patients may talk about things in the abstract; for example, a patient may say, "Having diabetes makes it hard for people to feel good about themselves." Here, there is no personalization of the problem. The differences between Level 1 and Level 2 can be sometimes observed by the patient's language. At both levels patients will describe themselves as vic- tims, but the patient at Level 1 has given up while patients at Level 2 are using their victimization to manipulate the world. Persons who get angry or passively aggressive do so because they have some feeling that their action will make a difference.

Self-blame can be misinterpreted as a high level of personal responsibility. For example, a patient may say "I know it is all my fault, I don't have the willpower to follow a diet." This statement is not a demonstration of personal responsibility rather it is an example of Level 2 blaming. When patients engage in self-blame they generally identify some immutable quality in themselves, e.g., lack of willpower, which they contend determines their behavior. This is a way of dissociating themselves (and therefore giving up responsibility) from a particular aspect of themselves. The self-blaming patient is saying in effect, "I can't be held responsible for not following a diet because my lack of willpower is beyond my control." Although patients who engage in extensive self-blame might score as high internals on a locus of control assessment they should be scored at Level 2 using the PR scale.

Crisis management. At Level 2 patients view a crisis as a threat to their self-concept. Patients at this level spend a substantial amount of energy in a crisis justifying themselves and making others wrong. For example, a patient hospitalized for ketoacidosis might claim that it is the doctor, the hospital, or his job that is to blame for his ketoacidosis.

Language. Patients' language at Level 2 is externally focused. They have not given up like a person at Level 1 , but are battling the opposition. They may say things like, "If it weren't for my doctor," or "If I didn't have diabetes." This is comparable to the bad carpenter who blames his tools rather than taking the responsibility for poor workmanship. "If" is a common word in patients' vocabulary when they are functioning at Level 2. 
Examples of Level 2 verbalizations are: "If my wife only care about my diabetes, I would be able to follow my diet." "This hospital is crummy. If it were better, I would be all right." "If I didn't have such a bad memory, I would test my blood glucose more often."

A cue to Level 2 verbalizations is when the patient implies that "if things were different, I would be all right."

\section{Example of a patient educator's interchange} with a patient functioning at Level 2.

Patient: "Nothing seems to go right. My husband doesn't care that I have diabetes."

Educator: "I hear your unhappiness. Have you tried to talk to your husband?"

Patient: "It wouldn't do any good. $\mathrm{He}$ wouldn't listen. If only he would care about something."

In this interaction, the patient sounds at first like a Level 1 person since the first response is at Level 1. But when offered direction by the instructor, she pins the responsibility on her husband. Thus she has not totally given up. Note however, that she doesn't say "if only he would care about me."'

\section{Level 3}

Patients at Level 3 verbalize some responsibility for themselves and their feelings, thoughts and self-care. Patients at this level show a partial commitment to personal responsibility. However, they blame others as often as they look to themselves for the cause of their problems. Patients at Level 3 may assume a personal focus some of the time and then cancel it when they feel threatened by searching for reasons why they are not responsible.

Energy. At Level 3 patients utilize their energy in a more productive manner than patients at Level 2. Personal growth can occur at Level 3. Patients' energy is directed toward making both discriminations about themselves and searching for the faults of others.
Focus. At Level 3 patients are focused inward some of the time and outward at other times. They search for right and wrong and may often be characterized as persons who try to be fair. Rather than looking at themselves and fully examining their role, they are concerned with who is really to blame. Thus patients at Level 3 may indeed be right about the wrongdoings of others, but they allow this knowledge to interfere with their understanding of themselves. For example, they may be right in assuming that their spouse is not sensitive to their illness, but they use this fact to justify their lack of self-care. A patient at Level 3 may say, "I really should lose 20 pounds, but my wife is always cooking fried food."

While patients at Level 2 are usually fully self-righteous, patients at Level 3 have a sense of fair self-rightcousness. Rather than battling the external blindly as at Level 2 , at Level 3 patients have a keen sense of the fairness and justice of a situation. These patients may more often be right than wrong in their perceptions and accusations, but they use those perceptions to blind themselves to a fully personal and responsible perspective. At Level 3 patients float in and out of personal responsibility looking at themselves when they feel safe and out at others when they feel threatened. Part of the difference between Levels 2 and 3 is that at Level 3 patients are threatened less, so their personal perspective is more frequent and for longer periods of time.

Crisis management. At Level 3 crises are viewed as both threats and opportunities for growth. A confrontation with a patient at Level 3 may precipitate an identity crisis about which they are defensive, followed by introspection and greater understanding of self. For example, diabetic patients functioning at Level 3, when confronted about a lack of self-care may react initially by blaming someone else, but eventually accept some responsibility for their self-care.

Language. At Level 3 patients use language 
that reflects their split focus to the external and personal. They balance between focusing on their role in the situation and actively blaming others. A key to a patient functioning at Level 3 is the use of the word "but." The statement before the "but" is generally one of accepting personal responsibility; however the statement that follows the "but" often cancels this responsibility. For example, a diabetic patient at this level might say "It is important to stay in good control, but you rarely have time to test your blood glucose if you're a busy person." Examples of Level 3 verbalizations are: "I know it is up to me, but diabetes is so complicated." "I should follow my diet, but I have to eat out a lot." "I know taking care of my diabetes is my responsibility, but if your doctor in insensitive it makes good self-care very difficult."

Example of a patient-educator interchange with a patient functioning at Level 3.

Patient: "Nothing seems to go right. Even my husband doesn't care that I have diabetes."

Educator: "I hear your unhappiness. I wonder, have you tried to talk to your husband."

Patient: "I know I should and I want to, but he is so slippery. He won't admit how he really feels."

Thus the patient in this situation sees her responsibility, but also maintains that her husband is just as responsible.

\section{Level 4}

At Level 4 patients believe in taking responsibility for their lives. At Level 4 patients' perspectives are personal more than they focus on the faults of others because they are capable of personal introspection. They rarely blame others for their circumstances, and they seldom depersonalize their problems with diabetes. The limitation of Level 4 is that although these patients believe in personal responsibility and want to be responsible they do not always translate their beliefs into action. They are intellectually responsible, but do not live a fully responsible life.
Energy. At Level 4 patients usually have an abundance of energy. These persons are often engaged in programs of physical, intellectual and/or spiritual growth.

Focus. At Level 4 patients focus inward more than outward. They spend a minimum amount of time focusing on the shortcomings of others. These patients seldom dwell on the negative aspects of diabetes nor do they spend time agonizing about the complications that might occur in the future.

Crisis management. At Level 4 crises are viewed as challenges. There may be some element of threat in a crisis but patients at Level 4 have confidence in their ability to respond successfully. Patients at this level use crises to look into themselves and learn and grow.

Language. At Level 4 patients' language is focused on themselves. The word " $I$ " is used frequently and responsibly. They do not externalize their lives nor blame others for their problems. Examples of Level 4 verbalizations are: "I know it's up to me to lose weight." "I have been letting my control slip and I need to improve." "I'm annoyed because I have forgotten to test my blood glucose lately."

Example of a patient-educator interchange with a patient functioning at Level 4.

Patient: "I feel bad. I can't seem to get along with my husband. He doesn't seem to care that I have diabetes."

Educator: "I hear your unhappiness. I wonder, have you tried to talk to your husband."

Patient: "I am going to. It may be uncomfortable but $I$ know it is up to me, and I am going to do it."

In this exchange the patient is able to use the direction immediately. She uses the direction offered by the educator to take greater responsibility.

\section{Level 5}

At Level 5 patients accept total responsibility for their lives. They acknowledge diabetes 
as a fact of their lives and they do not waste energy resisting their diabetes or its self-care. They freely understand their contribution to their problems and experiences. They are usually accurate in their perceptions about others yet they do not dwell on how other people have contributed to their problems. At Level 5 patients take responsible action to solve their problems and they accept the consequences of both their behavior and outlook on life.

Energy. At Level 5 patients are operating at their peak most of the time. They have usually committed themselves to whatever effort is required to manage their diabetes. At Level 5 patients seldom waste resources for they know that they are responsible for their health and personal growth.

Focus. At Level 5 patients are sensitive to feedback from others, but do not allow themselves to be ruled by it. When these patients make a decision about a situation, they act on the decision and are not tormented by doubt. If they make a mistake, they use that information to redirect their future behavior, and do not mourn over their past ineffectiveness. At Level 5 patients seldom yield to social pressure. If drinking alcohol or eating sweets is the social norm, they do not feel obligated to join in. At Level 5 patients are very selfaware. They are continually finding ways to express and increase their personal responsibility. They examine their role in all situations and use their understanding to live a healthier, more responsible life.

Crisis management. Crisis points or what would be crisies for patients functioning at lower levels are seen as an opportunity for growth for patients at Level 5 . These patients are fully able to use information about themselves immediately. If they decide that the resources of a diabetes educator are needed to help solve a problem, they ask for help but take the responsibility for implementing the solution.

Language. At Level 5 people speak openly about themselves. They are seldom concerned with speculations about others. Examples of Level 5 verbalizations are: "Diabetes provided me with the opportunity to take much greater responsibility for my health." "Since getting diabetes I have developed a new understanding of the way my body uses food." "Confronting adversity has given me the opportunity to become a more caring person." "Diabetes has helped me rediscover how much I value feeling well."

Example of a patient-educator interchange with a patient functioning at Level 5.

Patient: "I feel bad. I don't seem to get along with my husband. He is not sensitive to my diabetes."

Educator: "I hear your unhappiness. I wonder, have you tried to talk to your husband."

Patient: "Yes, I am committed to communicating with him until we resolve this issue. I realize I have been upsetting myself about his beliefs concerning my diabetes."

Thus her final remark, although not conceding to her husband, shows how she uses the conflict to define her feelings more clearly. (This may be a somewhat artifical example since a diabetic patient at Level 5 would probably not be in this situation.)

\section{State and trait personal responsibility}

There are two major types of personal responsibility, state and trait. Trait personal responsibility refers to a person's ongoing overall world view. That is, each of us tends to have an overall level of personal responsibility that characterizes our outlook on life. This world view tends to be fairly imbedded in our personality and generally changes very slowly, if at all. A newly diagnosed patient who has an overall view of himself as a victim will most likely view himself as a victim of diabetes as well.

State PR refers to a situation specific and often temporary level of personal responsibility. The development of a complication of diabetes could precipitate a crisis to which the patient responds by assuming a lower level of 
personal responsibility. Depending on the magnitude of the crisis, patients tend to work through their problems and return to their previous higher level of personal responsibility. For example, a patient who discovers she has proliferative retinopathy may experience a period of mourning and depression during which she feels helpless and hopeless. However, if she generally functions at a higher trait level of personal responsibility she can be helped to work through these feelings and return to her previous level of personal responsibility. It is very unlikely that patients' level of personal responsibility about their diabetes will be any higher than their trait level of responsibility.

\section{Assessing the patient's level of personal responsibility}

Assessing a patient's level of personal responsibility should utilize data gathered during an indepth personal interview. The protocol used most often for assessing the patient's level of personal responsibility is to show the patient a card with the following sentence stem and five completion words written on it: "Having diabetes is a . . . . . Disaster, Burden, Problem, Challenge, Opportunity." Patients are then asked to choose which of the five words best describes their experience of having diabetes. Many patients will respond by saying that a number of the words describe having diabetes, at which point the educator should ask, "But which one word best provides an overall description of your experience of having diabetes?" When the patient chooses a word, the educator uses the answer to initiate a discussion of the patient's perspective. For example, if the patient were to choose the word "burden"' the educator would respond. "Tell me about why you view your diabetes as a burden."

Each of these five words is keyed to a different level of personal responsibility, i.e. Disaster $=$ Level 1, Burden $=$ Level 2, Prob- lem $=$ Level 3, Challenge $=$ Level 4, Opportunity $=$ Level 5 . However, an educator cannot assess a patient's level of personal responsibility simply by using a one word answer. It is important to discuss the patient's view of diabetes in an indepth manner and use the totality of his or her view of having diabetes to assess the level of personal responsibility. In determining levels of personal responsibility the educator should evaluate on the basis of the most frequent verbalizations by the patient, since patients may express a few statements characteristic of other levels.

In assessing the patient's level of personal responsibility the educator should create a mental summary of the patient's stated perspective on having diabetes and then compare it to the five levels in the PR scale. For example, after listening to a patient discuss his or her experience of having diabetes an educator would ask "Does this patient view himself as a helpless, hopeless victim totally overwhelmed by diabetes and life in general?" If the answer is "yes" the patient would be rated at Level 1. "Is the patient an angry, blaming victim of diabetes who claims that it is diabetes or other people who are the cause of all his or her problems?' In this case the patient would be rated at Level 2 . This process of mentally matching descriptions of each PR level with patients' presentations of themselves holds true for the other three levels as well.

If the patient's description of having and treating diabetes includes a mixture of two PR levels, then the educator should rate a patient between the two levels, such as 2.5 or 3.5. As educators become more practiced completing PR assessments they will be able to make more precise ratings and will recognize the patient's level of PR as the patient describes having and treating diabetes. What is most important is that the educator is internally consistent. That is, if an educator rated a taped interview of a patient at Level 2 on one day it should be rated Level 2 if the educator rated the tape 3 days later. 
Rating a patient's level of personal responsibility accurately and consistently requires practice. A good method of practicing PR assessments is to audio tape interviews with patients and then review and rate the taped interviews. If two or more educators are learning to use the PR system they can listen to tapes together and discuss what PR level each would assign. As educators complete more ratings they will develop and enhance their ability to assess patients levels of personal responsibility.

Although this method of psychosocial assessment is more labor intensive than having patients complete written questionnaires, it has a key advantage which compensates for its cost in time and energy. Educators who learn to complete PR assessments will acquire a useful counseling skill. Once an educator has internalized the PR system he or she can identify a patient's level of functioning during an interview and respond immediately. The educator will be equipped to help patients explore the consequences of their views of diabetes and offer them opportunities to move to higher levels of personal responsibility.

Assessing patients' level of personal responsibility about diabetes is an appropriate part of an educational assessment. By conducting a pre and post program assessment of a patient's level of personal responsibility the educator can assess change. It is important to note that although self-care behavior tends to be consistent with a patient's level of personal responsibility, it is not always a good predictor of level of personal responsibility. For example, a patient at Level 2 could be very compliant with a recommended treatment regimen because of anxiety but simultaneously feel a geat deal of resentment towards the physician who prescribed the regimen. The patient's compliance in this situation might be driven by a fear of complications or the physician's disapproval. Although this patient's self-care could be considered good in the technical sense, his or her emotional and psychosocial adaptation to diabetes would have to be considered poor. Therefore the educator should focus on the patient's attitude and outlook about diabetes rather than on the technical aspects of diabetes self-care when conducting a PR assessment.

\section{Helping patients achieve higher levels of per- sonal responsibility}

At Level 1 the educator will probably have to work with other care givers (e.g., family) as patients at Level 1 accept virtually no responsibility for their diabetes care. Although the educator should be empathic and supportive of patients at Level 1, the psychological functioning of these patients usually requires referral to a psychiatrist, psychologist or other trained mental health professional. Level 1 patients are often found in institutional settings such as nursing homes and other long-term care facilities intended for patients who are unable to care for themselves.

Patients functioning at Level 2 are denying personal responsibility because they feel threatened. Anger and denial are classic examples of the fight and flight response to threat. If patients at Level 2 are confronted about their attitudes or self-care it will usually only increase their sense of being attacked and elicit defensive behavior. The educator can help patients at Level 2 by providing a warm, safe, psychologically secure environment in which they can explore and express their feelings about having and treating diabetes. The educator should be non-judgmental and not try to persuade or coerce patients to accept a higher level of personal responsibility. However, the educator can ask patients to explore the consequences of their attitudes and behavior and help them identify options which may lead to growth. Patients move to higher levels of personal responsibility naturally when they feel safe and have had an opportunity to work through the various 
emotions associated with having and caring for diabetes.

A number of educational techniques developed for counseling psychology and adapted for use in diabetes education should prove useful for helping patients learn to accept higher levels of personal responsibility for diabetes [14]. A useful model for working with Level 2 patients is exploration $\rightarrow$ insight $\rightarrow$ change. Patients can be encouraged to explore both the feelings and meaning of having diabetes through the use of values clarification techniques and other personal growth exercises. For example, patients can be asked to complete sentence stems such as: The most difficult thing about having diabetes is ... . They can be encouraged to share their answers and discuss the feelings associated with them. The major goal of this type of activity is to help people identify and accept their emotional and cognitive response to diabetes. When conducted in a non-threatening atmosphere, exploration of the personal meaning of having diabetes can result in patients having insights about the impact of their self-created emotional, cognitive, and behavioral responses to the disease. These insights can lead to changes in attitude and/or behavior that will improve the quality of their lives.

At Level 3, because patients are verbalizing some degree of responsibility, it is appropriate to provide both the emotional and psychological exploration just described for patients at Level 2 and a self-selected goal setting component. Because patients at Level 3 are able to accept partial responsibility they can be asked to choose their own self-care goals and make a commitment to meeting them. Goal setting should be integrated with opportunities to explore and express their feelings about the costs and benefits of taking responsibility for managing their own diabetes self-care.

At Levels 4 and 5, the educator can focus more on providing the intellectual and techni- cal resources that patients need to care for their diabetes. These patients are already functioning at a psychologically healthy level and continued growth can be expected as a natural outcome of their level of functioning. These patients are generally very rewarding to work with since they are highly motivated and willing and able to make use of the expertise provided by diabetes educators. Patients at the lower levels of personal responsibility tend to be much more challenging and frustrating. However, through patience and compassion the educator can make a very significant contribution to the growth and well-being of these patients as well as those functioning at the higher levels.

\section{Summary}

The most important thing to remember about personal responsibility is that it represents a psychological perspective or attitude, i.e., patients' views of themselves and their world. It is not about their circumstances. As is true for many people, patients with diabetes have circumstances that could justify a victim perspective. The problem with adopting a victim perspective is that it diminishes the quality of patients' lives because in assigning the responsibility for their thoughts, feelings and behavior to their diabetes they give up the power to shape and master their own lives. People will often point out that a certain person really is a victim of circumstances, which may be true. However, having the psychological perspective of oneself as a victim is an unhappy and frustrating experience. The point is that no matter what the circumstances are in any of our lives we have choices about how to feel, think and act about those circumstances. Our choices are important and have an impact on the quality of our lives and those around us. The purpose of assessing patients' level of personal responsibility is to help them discover their capacity to make choices that will empower and enrich their lives. 


\section{Acknowledgment}

This paper was supported in part by the National Institutes of Health Grant 3P60AM20572, National Institute of Diabetes, Digestive and Kidney Diseases.

\section{References}

1 Anderson RM, Genthner RW, Alogna M: Diabetes patient education: from philosophy to delivery. Diabetes Educ 1982; 8: 33-36.

2 Villeneuve $M$, Lazansky $C$ : The impact of professional education on patient care outcomes. Diabetes 1985; 34: $166 \mathrm{~A}$.

3 Genthner RW: Personal responsibility, in R.H. Woody (Ed) Encyclopedia of Clinical Assessment. New York: Jossey Bass, 1980.

4 Genthner RW, Hart S: Three psychotherapies and their facilitation of personal responsibility, in R. Anderson (Ed) Helping Others Through Counseling Casework and Psychotherapy. Johnson City: East Tennessee University Press, 1979.

5 Anderson RM: The personal meaning of having diabetes: Implications for patient behavior and education of kicking the bucket theory. Diabetic Med 1986; 3(1): 9889.

6 Genthner RW, Jones DE: A scale for assessing personal responsibility: validity, reliability, and rater trainability. J Pers Assess 1976; 40: 269-275.
7 Genthner RW: An empirical investigation of the personal responsibility rating system. J Psychol 1976; 92: 53-56.

8 Horosz W: The Crisis of Responsibility: Man as the Source of Accountability. Norman: University of Oklahoma Press, 1975.

9 Rogers C: On Becoming a Person. Boston: Houghton Mifflin Co., 1961.

10 Anderson RM, Genthner RW: Testing your attitude. Diabetes Forecast, September 1989, 83-87.

11 Anderson RM, Saunders JT: What diabetes means to you. Diabetes Forecast, May 1987, 21-23.

12 Maslow AH: Toward a Psychology of Being. New York: D. Van Nostrand Co., 1968.

13 Rogers C: Client-Centered Therapy. Boston: Houghton Mifflin Co., 1965.

14 Anderson RM, Nowacek G, Richards F: Influencing the personal meaning of diabetes: Research and practice. Diabetes Educ 1988; 14: 297-302.

Correspondence to:

R.M. Anderson

University of Michigan Diahetes Research and Training Center University of Michigan Medical Center

Towsley Center, Box 0201

Ann Arbor, MI48109-0201, USA 